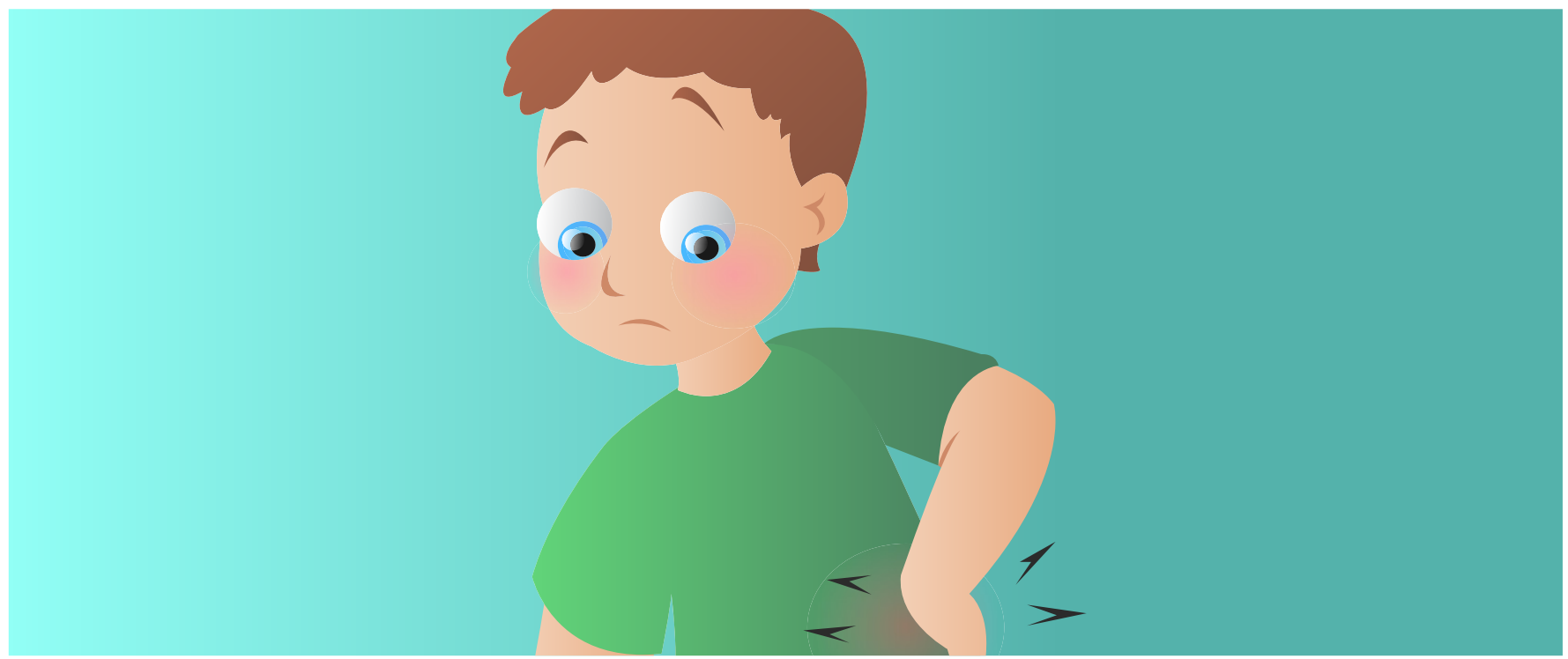

\title{
WHAT IS SPINAL CORD INJURY?
}

\section{Madeleine O'Higgins' ${ }^{1}$, Anna Badner ${ }^{1,2}$ and Michael G. Fehlings ${ }^{1,2,3^{*}}$}

${ }^{1}$ Krembil Research Institute, Toronto Western Hospital, University Health Network, Toronto, ON, Canada, ${ }^{2}$ Faculty of Medicine, Institute of Medical Science, University of Toronto, Toronto, ON, Canada, ${ }^{3}$ Department of Neurosurgery, University of Toronto, Toronto, ON, Canada

\section{REVIEWED BY:}

NOA

10 YEARS OLD
The spinal cord is a pathway for messages to and from the brain and other parts of the body. It has nerve cells called neurons that are divided into white matter, which has a fatty white coating called myelin, and gray matter. The spinal cord is protected by the bony spine. When the spinal cord is injured, the injury happens in two stages: the first of these is the actual injury where the cord is bruised or torn and the second is known as the secondary injury. The secondary injury includes a few different reactions that happen in the body because of the bruising and tearing. Spinal cord injuries can cause a person to lose feeling or use of their arms and legs, so scientists are working to find different ways of stopping or reducing the secondary injury to help people with spinal cord injuries recover better.

\section{WHAT IS THE SPINAL CORD AND HOW DOES IT WORK?}

The spinal cord is very important. It is the main pathway for information to travel between the brain and all the other parts of the body. Through this communication, we are able to feel sensations, like pain, and control the movement of our arms and legs. These messages (traveling to and from the brain) 
NEURONS

The specialized cells in the central nervous system.

\section{MYELIN SHEATH}

The white fatty coating surrounding some neurons that helps the messages travel between neurons.

\section{WHITE MATTER}

Central nervous system area composed of neurons covered with myelin sheath.

\section{GRAY MATTER}

Central nervous system area made up of neurons not covered in myelin and the cell bodies (central part of the cells).

\section{VERTEBRAE}

The small bones that make up the bony spine.

\section{FIGURE}

The structure of a neuron, the specialized cells of the brain and spinal cord. The neurons may also have a white fatty coating, known as the myelin sheath, which helps the messages travel to the brain more quickly. are sent by specialized nerve cells, called neurons (Figure 1). The neurons may also have a white fatty coating, known as the myelin sheath (my-uh-lin sheath), which helps the messages-like the pain from someone standing on your toe-to travel to the brain more quickly. Most of the neurons with myelin are found in an area of the spinal cord known as white matter and they surround the cells without myelin, which are located in the area called the gray matter.

If you look at a piece of spinal cord that has been cut (as a cross section, meaning a slice through the spinal cord, like you might slice a carrot or a hot dog to show the inside), the gray matter makes an " $\mathrm{H}$ " or butterfly shape inside the white matter (Figure 2A). The gray matter also contains most of the spinal cord blood vessels, which provide nutrients and oxygen to the neurons. Also important is the bony spine or backbone, which protects all the cells and structures of the spinal cord. This backbone, made up of smaller bones called vertebrae (ver-tuh-bray), keeps the spinal cord safe from any bashes and bangs. The vertebrae are organized into levels (cervical, thoracic, lumbar, and sacral), based on where they are in comparison to the head and the tail bone (Figure 2B). Each of these spinal cord levels controls the movement and feeling of a particular body area. The cervical level, closest to the head, controls the upper body, while the thoracic and lumbar segments are responsible for the lower body. As a result of these functional differences, spinal cord segments are different sizes and have different amounts of gray and white matter (Figure 2C).

Like any other part of your body, the spinal cord can be injured. Some people damage their spinal cords when they dive into a swimming pool that is too shallow for diving, or even in a traffic accident. When the spinal cord is damaged, the messages from the brain cannot travel to the rest of the body. Therefore, after a spinal cord injury, the brain may no longer be able to send messages to the legs and the affected person may lose his ability to walk. A higher injury, where the spinal cord is damaged closer to the neck (in the cervical level), may cause even more severe problems and some people are left unable to move their arms. Worst of all, the cells in the spinal cord are very sensitive, and this damage is often permanent, meaning it cannot be fixed.

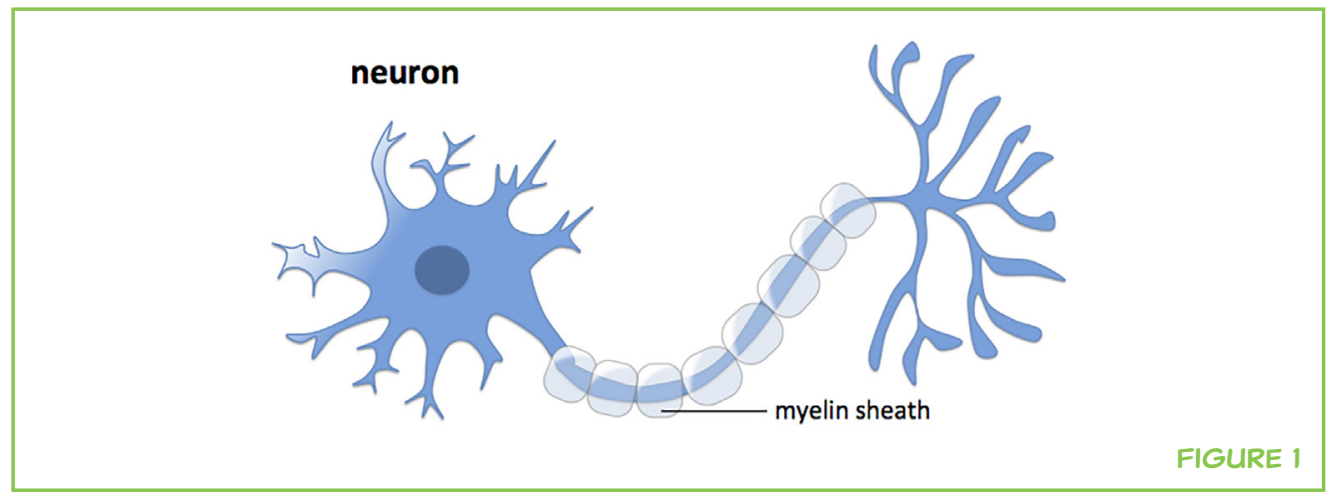




\section{FIGURE 2}

The bony spine, made up of individual bones called vertebrae, protects the soft and sensitive spinal cord. A. Within the spinal cord, cells with myelin are found in the white matter, while those that lack myelin are found in the gray matter. The gray matter makes an "H" or butterfly shape inside the white matter. B. Spinal cord vertebrae are organized into distinct segments, with control over specific body parts. In humans, there are 8 cervical, 12 thoracic, 5 lumbar, and 5 sacral vertebrae. C. The spinal cord segments are also different sizes and have a distinct amount of gray and white matter.

\section{ISCHEMIA}

Reduced blood flow to cells that causes a shortage of oxygen and glucose.

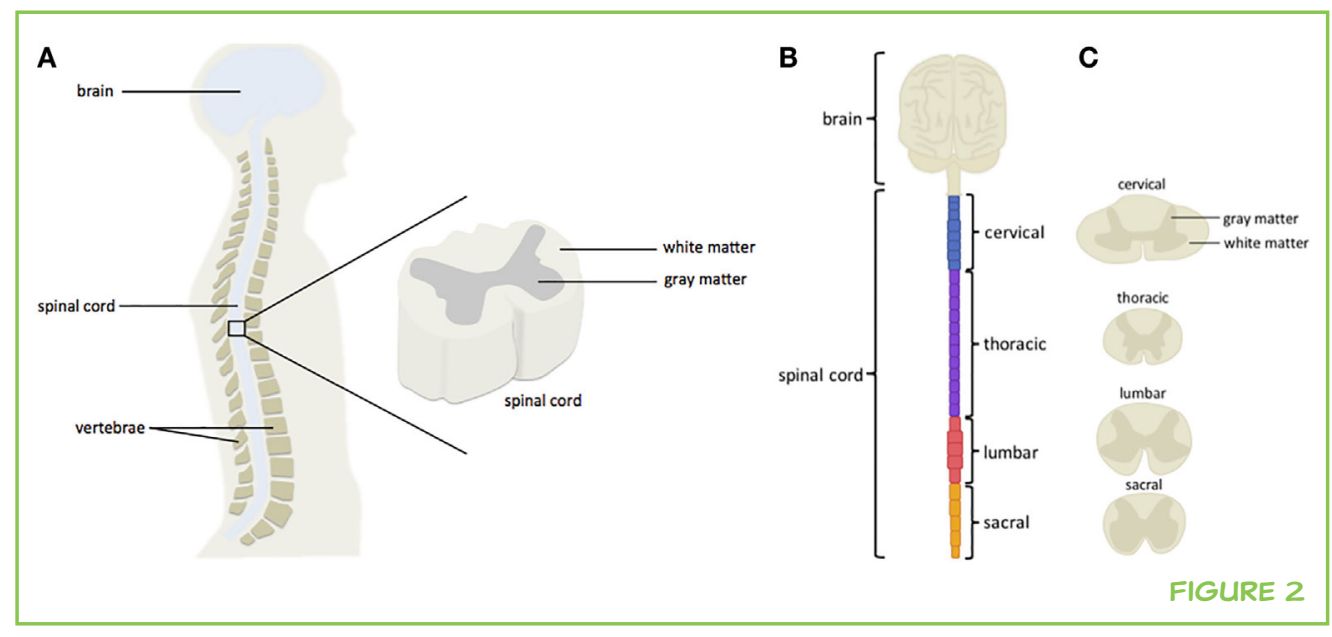

In the United States of America, it is estimated that there are about 906 people living with a spinal cord injury for every million people in the country. More than half of these spinal cord injuries are at the cervical level, and most people who get these injuries are aged between 15 and 30 when it happens [1]. However, it is important to remember that these numbers are changing over time. For example, as people are now living longer, there are bigger numbers of spinal cord injuries happening to older people when they slip or fall.

Since spinal cord injury has serious, and often permanent, consequences a lot of research has been done to try to discover ways to help people recover. While being safe-wearing seatbelts when traveling and not diving into shallow water-can help to prevent accidents, we cannot avoid all accidents and so we need to find ways to help people recover.

\section{WHAT HAPPENS IN THE SPINAL CORD DURING INJURY?}

A lot of important research on spinal cord injury has been done by two neurosurgeons, Dr. Charles Tator and Dr. Michael Fehlings [2-4]. They discovered that damage to the spinal cord continues after the initial accident, when the spinal cord is first torn and bruised upon impact (Figure 3). This means that, even after the injury, there are things happening in the spinal cord that increase the amount of damage. Together, these delayed events are known as the secondary injury. Therefore, the "primary" or first injury is what causes the damage to the spinal cord and the secondary injury is the body's response to this damage, which causes more harm.

Shortly after the initial injury, secondary injury begins when blood stops flowing to the cells in the spinal cord-this lack of blood flow is called ischemia (is-keem-ee-ah). Because many blood vessels-the tubes that carry the blood-are damaged by the injury, there is no more active blood flow to bring the oxygen and nutrients that neurons need to survive. 


\section{FIGURE 3}

There are two phases of injury after damage to the spinal cord. The primary injury refers to the initial damage to the spinal cord, where the issue is torn and bruised upon impact. As the body tries to respond to the accident, secondary injury takes place and increases the amount of spinal cord damage.

\section{NEUROTRANS-}

\section{MITTERS}

Special chemicals that help neurons communicate, the chemical messengers of the nervous system.

\section{EXCITOTOXICITY}

Where neurons become damaged when too much of a neurotransmitter is released.

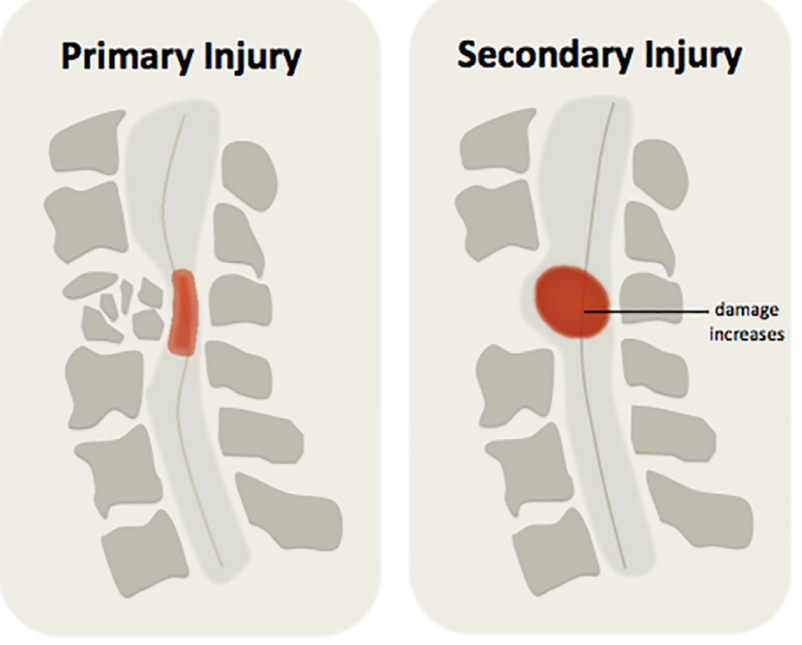

FIGURE 3

Without this, the still-healthy cells, which were unaffected by the primary injury, may also die. Ischemia can also cause the surviving neurons to lose their myelin (the fatty coating), making it harder for messages to be sent to the brain.

During secondary injury, the immune cells (cells of the body's defense system), which help to clean up the dead cells, can also cause more damage to the spinal cord. While this cleanup is important for recovery after spinal cord injury, the immune cells work for longer than they are needed, causing more harm by killing healthy neurons. The immune cells also release chemicals, including specialized molecules that send signals throughout the body, which bring even more immune cells into the injured area, making it harder for the body to heal itself. The immune cell activity and the release of their signaling molecules are jointly called inflammation (in-flam-ay-shun).

Another source of damage during secondary injury results from weakened neuron communication. Neurons communicate with each other by releasing specialized chemicals, referred to as neurotransmitters (new-ro-trans-mit-ers). After spinal cord injury, this neurotransmitter release goes haywire, causing too much release of these chemicals. As neurons are activated by neurotransmitters, they become overactivated (over-excited) and damaged. This type of neuron damage is called excitotoxicity (ex-syto-tox-iss-itty).

To summarize, initial spinal cord damage is worsened by secondary injury, which includes ischemia (Figure 4A), inflammation (Figure 4B), and excitotoxicity (Figure 4C). 


\section{FIGURE 4}

Secondary injury after spinal cord damage involves ischemia, inflammation, and excitotoxicity. A. Blood carries oxygen and nutrients to the cells of the spinal cord. Ischemia refers to reduced blood flow, and therefore less oxygen, which causes healthy cells to die.

B. Inflammation describes the immune (body's defense system) response to injury, where immune cells help to clean up dead cells and debris. Unfortunately, the immune cells work for longer than they are needed, causing damage to healthy neurons. Immune cells also release special signaling molecules that bring even more immune cells, making it harder for the body to heal itself.

C. Excitotoxicity is a specific type of neuronal injury, caused by haywire neurotransmitter release. In the presence of excess neurotransmitter, neurons become over-activated (over-excited) and damaged.

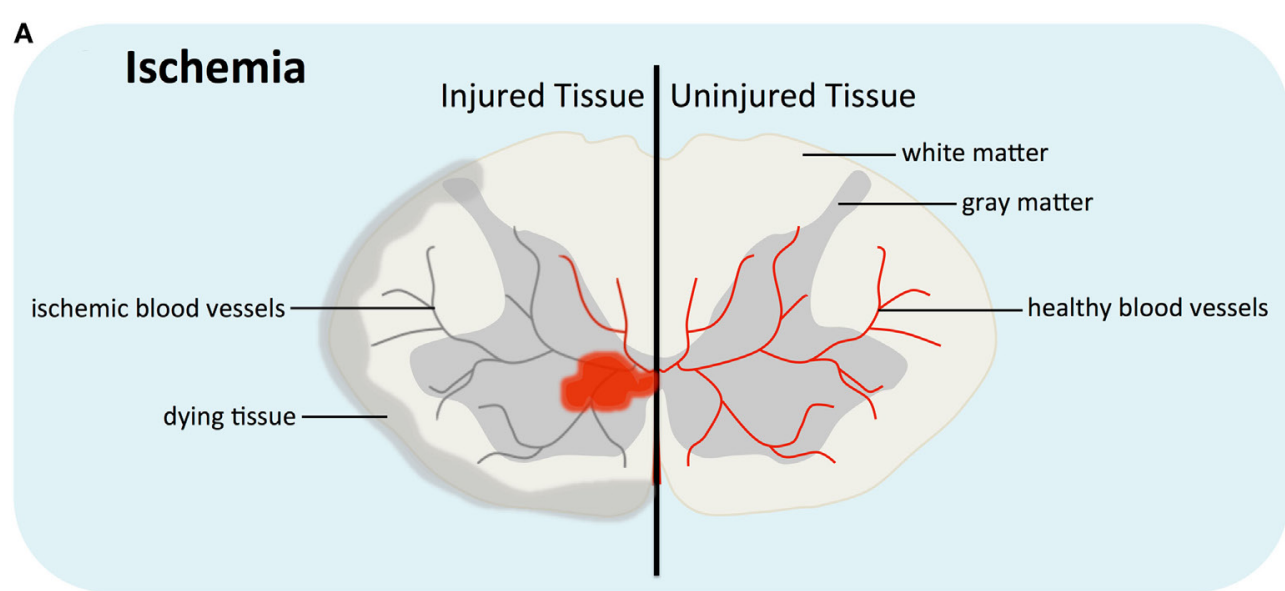

B Inflammation

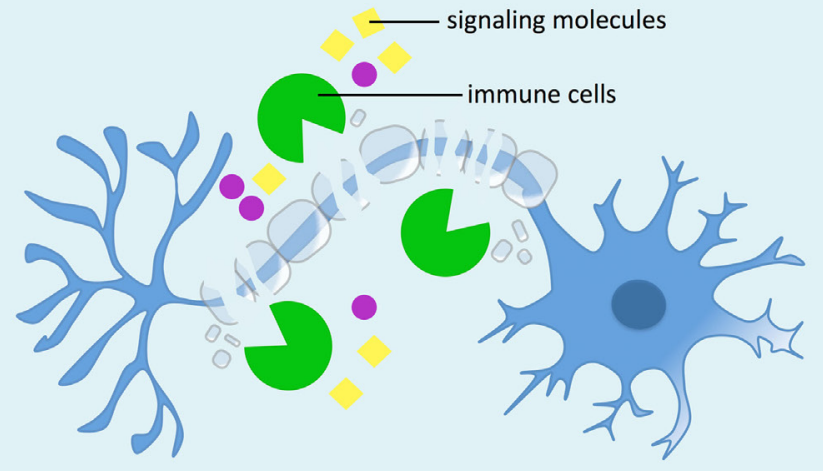

C

\section{Excitotoxicity}

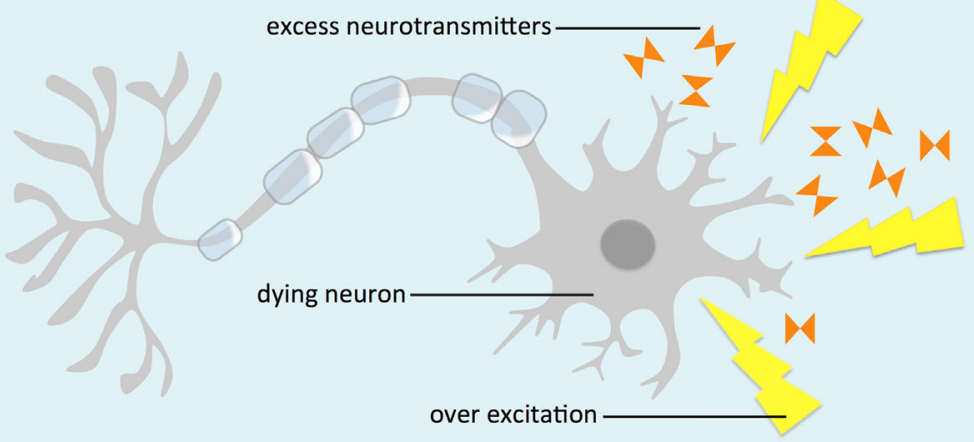

FIGURE 3

\section{HOW MIGHT THIS HELP US TO TREAT INJURED SPINAL CORDS?}

The good news is that the more that researchers understand about spinal cord injury, the better chance they have to find treatments that will improve recovery. One of the ways that surgeons try to reduce secondary injury is through early surgery. By removing pressure from the spinal cord as soon as possible, they can prevent some of the tissue damage that happens during second- 


\section{NEUROPROTECTION}

a process of protecting neural tissue from the secondary injury.

\section{NEURAL STEM}

\section{CELLS}

cells that are able to regrow themselves and develop into cells of the nervous system (such as neurons and glia). ary injury. Researchers are also studying medicine that can be given to help stop some of the damaging effects of the secondary injury. But this treatment approach, called neuroprotection [5, 6] (new-ro-prot-ek-shun), can only be used for a short time frame after the initial injury. After extended periods of time, when neuron death has already happened, different treatment strategies are needed. Some researchers are looking at replacing the lost neurons by transplanting neural stem cells (stem cells are a type of cell in the body that are able to develop into different cell types, "neural stem cells" are stem cells which can develop into the different types of cell found in the central nervous system) $[4,7]$, although a lot more research is needed before this can be safely applied in patients. Overall, the more scientists and doctors understand about spinal cord injury, the more ways we can find to help patients recover.

\section{REFERENCES}

1. Singh, A., Tetreault, L., Kalsi-Ryan, S., Nouri, A., and Fehlings, M. G. 2014. Global prevalence and incidence of traumatic spinal cord injury. Clin. Epidemiol. 6:309-31. doi:10.2147/CLEP.S68889

2. Tator, C. H., and Fehlings, M. G. 1991. Review of the secondary injury theory of acute spinal cord trauma with emphasis on vascular mechanisms. J. Neurosurg. 75(1):15-26. doi:10.3171/jns.1991.75.1.0015

3. Wilson, J. R., Forgione, N., and Fehlings, M. G. 2013. Emerging therapies for acute traumatic spinal cord injury. CMAJ 185(6):485-92. doi:10.1503/cmaj.121206

4. Ahuja, C. S., and Fehlings, M. 2016. Concise review: bridging the gap: novel neuroregenerative and neuroprotective strategies in spinal cord injury. Stem Cells Transl. Med. 5(7):914-24. doi:10.5966/sctm.2015-0381

5. Chen, S., and Levi, A. D. 2017. Restorative treatments for spinal cord injury. Neurosurg. Clin. N. Am. 28(1):63-71. doi:10.1016/j.nec.2016.08.004

6. Hilton, B. J., Moulson, A. J., and Tetzlaff, W. 2016. Neuroprotection and secondary damage following spinal cord injury: concepts and methods. Neurosci. Lett. doi:10.1016/j.neulet.2016.12.004

7. Iyer, N. R., Wilems, T. S., and Sakiyama-Elbert, S. E. 2017. Stem cells for spinal cord injury: strategies to inform differentiation and transplantation. Biotechnol. Bioeng. 114(2):245-59. doi:10.1002/bit.26074

SUBMITTED: 09 February 2017; ACCEPTED: 20 April 2017; PUBLISHED ONLINE: 09 May 2017.

EDITED BY: Rich Ivry, University of California, Berkeley, USA

CITATION: O'Higgins M, Badner A and Fehlings MG (2017) What Is Spinal Cord Injury? Front. Young Minds 5:17. doi:10.3389/frym.2017.00017

CONFLICT OF INTEREST STATEMENT: The authors declare that the research was conducted in the absence of any commercial or financial relationships that could be construed as a potential conflict of interest. 
COPYRIGHT ( 2017 O'Higgins, Badner and Fehlings. This is an open-access article distributed under the terms of the Creative Commons Attribution License (CC BY). The use, distribution or reproduction in other forums is permitted, provided the original author(s) or licensor are credited and that the original publication in this journal is cited, in accordance with accepted academic practice. No use, distribution or reproduction is permitted which does not comply with these terms.

\section{REVIEWED BY}

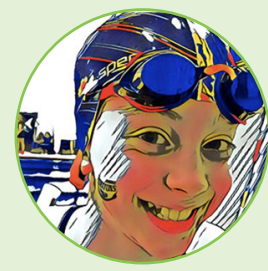

\section{NOA, 10 YEARS OLD}

I love sports. My favorite sport is swimming but I also play lacrosse and have run seven $5 \mathrm{Ks}$. I also enjoy traveling with my family.

\section{AUTHORS}

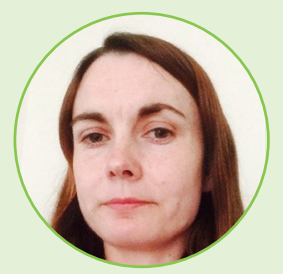

\section{MADELEINE O'HIGGINS}

Madeleine O'Higgins specializes in research communications for the Fehlings team and really enjoys writing and re-writing science and research for different audiences. She studied psychology and completed a PhD and post-doctoral fellowship in the field before coming to work on the Fehlings research team.

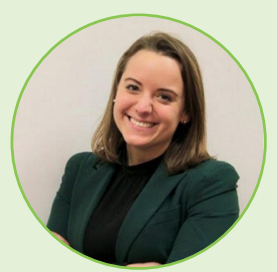

\section{ANNA BADNER}

Anna Badner is a PhD student at the Institute of Medical Science in the University of Toronto, under the supervision of Dr. Michael G. Fehlings. She studies traumatic spinal cord injury and potential stem cell treatments for neuroprotection. Outside of the lab, she enjoys hiking, skiing and photography.

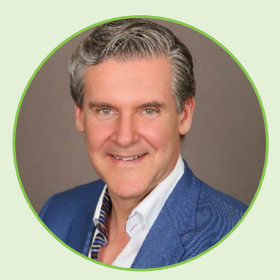

\section{MICHAEL G. FEHLINGS}

Dr. Michael G. Fehlings is a Professor of Neurosurgery at the University of Toronto. As Head of the Spinal Program at Toronto Western Hospital, he combines seeing patients and doing spine surgery with overseeing a research program focused on discovering novel treatments for the injured brain and spinal cord. With over 700 publications, he is established as a leading international expert investigating central nervous system repair and regeneration for brain and spinal cord injury. *michael.fehlings@uhn.ca 